\title{
Study on the Quality of Grain Seeds from the Perspective of Government Regulation_-Based on the Research of Shandong Province GENG GE FENG
}

\author{
Zao Zhuang University, Zao Zhuang ,China \\ ggf1403@126.com
}

\begin{abstract}
Key words: government regulation, seed quality, seed enterprise, seed market, seed administrative organ, suggestion
\end{abstract}

\begin{abstract}
Agriculture is an important issue related to people's livelihood, the seed is the lifeblood of agriculture, so the quality of grain seed supervision is particularly prominent.In this paper, we mainly investigate the seed enterprises, seed sales market, the seed of the administrative organs, and put forward the government regulation on the quality of grain seed close relationship.Shandong province is a major province of grain production in Shandong province for investigation and analysis of the status of seed quality has certain reference significance for the orderly development of national seed industry.
\end{abstract}

\section{Introduction}

"The country takes the agriculture as the foundation, and the agriculture as the seed", which shows the important position of the seed quality problem in the development of the country. With the development of science and technology and the development of market economy in our country, the seed industry of our country is facing great challenge.

\section{Government regulation and seed quality management}

At the end of the 1990s, Chinese scholars began to study the theory of government regulation. After nearly 20 years of efforts, it has basically formed an independent disciplinary status of government regulation. Government regulation involves the interests of the government, enterprises, the public, regulation is the balance of interests of these three parties, regulation itself is a game rule. The behavior of government regulation can be studied by the theories and methods of economics, sociology, politics, law and so on.From the perspective of government regulation, this paper studies the problem of grain quality in Shandong Province, and provides effective solutions for the practical problems.

In 2005, ISO9000 (ISO), the quality management system foundation and terminology, defined the quality of a set of inherent characteristics to meet the requirements. "Inherent property" is something that has already existed, especially permanent. Therefore, the quality of seed content is very wide. It can be expressed from two aspects: internal quality and external quality. The internal quality mainly includes two aspects: the variety attribute and the sowing quality. High quality seeds should have good varieties and good sowing quality. External quality includes labels, packaging quality and measurement, corporate commitment, etc.

\section{Design, implementation and result analysis}

3.1 Object of study. In this study, the research object mainly includes three types of seed enterprises, seed sales market, seed management organization.The seed market in Ji'nan, Heze, Yantai, Dezhou and Zaozhuang was investigated. Mainly through the research and management of stores and consumers to collect first-hand data, and the focus of the special consumer groups.

3.2 research method. Using a questionnaire survey, telephone consultation, consumer forum, access to the yearbook data, sample checks, visit the seed production enterprises, research and other 
forms of seed management institutions. The seed quality data, the official access to seed company relevant literature data obtained, conducted a comprehensive summary, in order to understand the status of seed quality in Shandong province. Also to the seed industry managers, seed business operators to consult to understand their opinions and suggestions to improve the quality of seeds.

3.3 Analysis of seed quality in Shandong. Shandong province is a big province of crop seed industry, annual seed use amounted to 1 billion 800 million kilograms. The seed quality and efficiency is the pre condition for food security. Seed quality is the focus of current seed market management. Learned from the Shandong seed management station of the official data, the pass rate of seed quality in consecutive years stable at more than $97 \%$ years without major cases have occurred, the seed market stable, adequate supply of seeds.

\section{Analysis on current situation of Grain Quality Supervision in Shandong}

4.1 Analysis on the present situation of seed management enterprises in Shandong. There are a large number of seed enterprises in Shandong Province, but the scale is small. According to the data obtained from the Shandong province seed management station, the enterprise was classified according to the registered capital.Among them, the largest number of enterprises from 1 million to 5 million yuan, accounting for the proportion of the total registered capital of 5.56\%. Although the number of enterprises of more than one billion yuan, although only 5 , but accounted for the total registered capital of $19.26 \%$.

\subsection{Analysis of seed market in Shandong}

\subsubsection{Investigation of seed management households}

The research group conducted a questionnaire survey on 53 operating stores in the research area. The main reasons for the existence of the seed market were classified and analyzed.From the survey results, that is "subject behavior chaos" 46.53\%; "that many varieties, mixed with $86.32 \%$; that" label false, false propaganda content "of $32.55 \% ; 11 \%$ of the people think that" dealer integrity "; $18.16 \%$ of people think that" seed poor quality "; another $13.05 \%$ people choose" decks infringement". From these data show that there are many varieties of seed market, chaos, miscellaneous, the main problem for farmers to choose the seed caused a great obstacle, the need for government to strengthen supervision.

\subsubsection{Survey of farmers}

The research group conducted a questionnaire survey on farmers. A total of 600 questionnaires were sent out, with a total of 580 copies and a valid questionnaire of 561 . The effective recovery rate was $96.7 \%$. Also focus on the cultivation of large, poor households and village cadres.

4.3 Investigation and analysis of seed administration department in Shandong. From the institutions, seed management institutions are not smooth. From the point of view of China's seed management institutions: the Ministry of agriculture set up Seed Management Bureau, provincial, city and county have the corresponding seed management institutions. In Shandong Province, the regulatory authorities as well as agricultural law enforcement agencies generally only to the county level, some local staff, hardware equipment can be difficult to fully equipped for the vast rural market regulatory enforcement is relatively large.

\section{Research conclusions and recommendations}

In order to improve the quality of seeds, and to protect the legitimate rights and interests of production operators and users, in order to improve the quality of seeds in Shandong province. In order to set up the concept of "sustainable supervision", and make the supervision to the normalization and standardization, the paper puts forward the corresponding suggestions.

\subsection{Strengthen government supervision of Seed Enterprises}

\subsubsection{Strengthen the supervision of breeding links}

Seed industry to achieve pre regulation, supervision and supervision in the matter afterwards. In the breeding link, formulate strict regulatory norms, to stop the deck breeding behavior of individual enterprises; strengthen the country on foreign and domestic research institutions 
cooperation breeding supervision, protection of intellectual property rights, to avoid the use of foreign capital multinational companies squeeze the living space of domestic enterprises, so the monopoly of the seed industry; combat interests or personal FanLuan seed the behavior of.

\subsubsection{To strengthen the supervision of the production process}

According to the principle of "who issued the certificate to clean up", the enterprises that have issued the seed production and operation license have been examined one by one. In the seed production process, to strengthen the supervision of production enterprises in the region, to combat illegal production without a license or unauthorized production.

\subsubsection{Play the role of industry associations}

Play the role of seed industry associations, establish a good reputation system. Enterprises in order to win a stable profit, the need to establish a long-term game thinking, if the consumer will be punished fraud, deception is more likely to be found and spread.

\subsection{Strengthen government regulation of seed market}

\subsubsection{Banned illegal operators to carry out special inspections of the seed market}

A comprehensive inventory of area seed stores comprehensive register. Ban undocumented households in the province, city and county border area and agricultural management center of key areas, rural peddlers as the focus, strengthen daily inspection. Follow up bad records. Especially in the past three years, the production and sale of counterfeit goods and the existence of decks infringement of substandard quality problems of the enterprise, as the focus of law enforcement supervision of seed.

\subsubsection{The establishment of the compensation mechanism}

Agricultural and business platform for shopping website to strengthen the guidance, to crack down on Internet sales of counterfeit and inferior seeds behavior, strengthening the supervision of advertising, to prevent false advertising to mislead farmers. For substandard products have entered the market, the timely release of warning information, take off the shelf, recovery and other coercive measures to prevent the inflow of agricultural production. Once the purchase of seed problems can be traced back to the production enterprise, you can start the crop compensation mechanism to reduce the economic losses of farmers.

\subsection{Reform and measures of Seed Administration}

\subsubsection{Clearly related to the main responsibility, do their job}

In January 1, 2016 to start the implementation of the new "seed law" more clearly: "the administrative department of agriculture is the main responsibility of seed management, other departments carry out their duties". First of all, in the agricultural system, establish detailed responsibilities, division of labor, efficient operation of the supervision system. In particular, the testing, testing units to develop strict management system to ensure that the test data is true and reliable.

\subsubsection{Establish and improve the quality inspection system.}

Provincial, city and county three testing agencies to clear division of labor, mutual coordination, flexible operation system. To make the seed quality management work into a systematic, procedural and standardized system. The detection ability of seed testing institutions shall be assessed, and the examination organization and the strict examination system shall be set up to improve the overall quality of the seed industry.

5.3.3 Improve the system of genetically modified seed production license, strengthen the implementation of seed quality certification system

In 2014, Chinese issued a central problem pointed out for positive research to "genetically modified agricultural products, independent innovation, careful promotion, to ensure safety, that the state is very cautious attitude". Establishment of transgenic safety management license system. Seed certification is the monitoring of seed quality by the third party certification organization. Genetic quality monitoring and seed quality monitoring. 


\section{References}

[1] Xiao Xingzhi, song Jing. Government regulation theory and policy [M] Dongbei University of Finance and Economics press, 2006

[2] Da Surin, money building [J] steel. The modern economic theory and explore the status of Chinese government supervision mechanism, 2006 (10)

[3] Liu Peng, Western Regulation Theory: a literature review and theoretical cleanup [J] China Administration, 2009 (9)

[4] on government regulation: International Comparison and Reform in China [J] Journal of Renmin University of China, 2007 (4) 